Artigo original

Hegemonia - Revista Eletrônica de Relações Internacionais do Centro Universitário Unieuro

ISSN: $1809-1261$

UNIEURO, Brasília, número 18, 2016, pp. 226-259.

Recebido em: 2/2/2016

Avaliado em:17/3/2016

Aprovado em: 19/4/2016

\title{
Políticas Públicas e Desenvolvimento Local: o caso do Programa Bolsa-Família
}

Renata Giovana Rech ${ }^{1}$, João Paulo Delmendes², e Michel Constantino ${ }^{3}$

RESUMO: As políticas públicas impactam na qualidade de vida dos indivíduos, nas comunidades, cidades, regiões e países. Este estudo procurou explorar os objetivos e resultados parciais do Programa Bolsa Família (PBF) do Governo Federal, analisando quais suas influências positivas e negativas no Desenvolvimento Local. Além disso, a pesquisa explora as formas de avaliação de políticas públicas que visam mensurar se os objetivos de determinado programa foi ou não atingido. O trabalho não visa esgotar os métodos de avaliação de políticas públicas, restringindo apenas à literatura que já avaliou resultados do Programa Bolsa Família. Inicialmente, trata-se do método por avaliação de impacto, cujo objetivo dessa modalidade é mensurar os impactos da intervenção do estado sobre o público-alvo dos programas e projeto sociais. Na sequência, demonstra-se a metodologia de Análise Envoltória de Dados (DEA) que tem como objetivo verificar a eficiência de determinado programa e todos os aspectos que ele visa atingir. Por fim, relata a mensuração do programa bolsa família através de regressão com modelos probabilísticos, que se baseia em econometria. Os resultados parciais encontrados na literatura demonstraram que o programa tem seus efeitos positivos no curto prazo, e, os estados que apresentaram maior índice de eficiência encontram-se na região Sul, seguida pelas regiões Sudeste e Centro-Oeste. Para um processo de desenvolvimento, o PBF, melhora as condições de vida das famílias

\footnotetext{
${ }^{1}$ Advogada e Nutricionista. Mestranda e bolsista no Mestrado em Desenvolvimento Local pela UCDB - MS.

${ }^{2}$ Advogado. Mestrando em Desenvolvimento Local pela UCDB - MS.

${ }^{3}$ Professor Doutor do Programa de Mestrado e Doutorado em Desenvolvimento Local - UCDB, Campo Grande, MS. michel@ucdb.br .
} 
Artigo original

Hegemonia - Revista Eletrônica de Relações Internacionais do Centro Universitário Unieuro

ISSN: $1809-1261$

UNIEURO, Brasília, número 18, 2016, pp. 226-259.

de baixo poder aquisitivo, porém torna-os dependente dos recursos recebidos.

Palavras-chave: Políticas Públicas; Bolsa Família; Desenvolvimento Local.

ABSTRACT: Public policies impact the quality of life for individuals, communities, cities, regions and countries. This study sought to explore the goals and partial results of the Bolsa Família Program (BFP) of the Federal Government, analyzing what their positive and negative influences on local development. In addition, the research explores the ways of evaluation of public policies that aim to measure whether certain goals or program was not reached. The work is not intended to exhaust the public policy evaluation methods, restricting only the literature that already rated results of the Bolsa Familia Program. Initially, it is the method for impact assessment, whose goal of this mode is to measure the state of the intervention's impact on the target audience of social programs and project. Following demonstrates to data envelopment analysis (DEA), which aims to determine the particular program efficiency and all aspects that it aims to achieve. Finally, reports the measurement of the scholarship program through family regression with probabilistic models, which is based on econometrics. Partial results reported in the literature have shown that the program has positive effects in the short term, and the states that had higher efficiency ratio are in the South, followed by the Southeast and Midwest. To a process of development, BFP, improves the living conditions of low-income families, but makes them dependent on the funds received.

Key-Words: Public policy; Bolsa Familia; Local development.

\section{INTRODUÇÃO}

O desenvolvimento é influenciado diretamente e indiretamente por políticas públicas, que impactam a vida dos indivíduos, os resultados das empresas e a sustentabilidade dos recursos ambientais. Nesse contexto, é fundamental pesquisar políticas 
Artigo original

Hegemonia - Revista Eletrônica de Relações Internacionais do Centro Universitário Unieuro

ISSN: $1809-1261$

UNIEURO, Brasília, número 18, 2016, pp. 226-259.

públicas que afetam de alguma forma o desenvolvimento local e métodos científicos que podem mensurar as externalidades geradas por essas políticas.

Para a teoria do desenvolvimento local, o apoio de organizações externas e organizações públicas são bem-vindas ao processo de desenvolvimento, porém, essa participação deve se restringir a apoiar, capacitar, alavancar e construir de forma horizontal e colaborativa o empoderamento da sociedade.

O objetivo desse artigo é desenvolver uma pesquisa exploratória do Programa Bolsa Família (PBF) do Governo Federal, e sua convergência e/ou divergência em relação à teoria do Desenvolvimento Local. Além disso, descrever os principais métodos utilizados para mensurar o impacto dessa política.

Vários estudos já foram realizados sobre o Programa Bolsa Família (PBF), e o mais abrangente foi o livro publicado pelo Instituto de Pesquisa Econômica Aplicada - IPEA em 2013 de autoria de Campello e Neri, esse último então presidente do IPEA e Ministro de Assuntos Estratégicos nesse período. O estudo foi realizado em comemoração aos 10 anos do Programa Bolsa Família (PBF).

Neste estudo exploratório serão analisados também outras publicações. E para organizar a pesquisa, este artigo foi dividido nessa seção introdutória, na seção II que trata da revisão teórica do PBF, na seção III a teoria do Desenvolvimento Local, na seção IV a teoria do Desenvolvimento Local e as Políticas Públicas, na seção V o estudo das Políticas Públicas e seus métodos de avaliação todas ligadas direta e indiretamente com o Desenvolvimento Local. Por fim metodologia, resultados e discussão sobre a implantação do PBF e 
Artigo original

Hegemonia - Revista Eletrônica de Relações Internacionais do Centro Universitário Unieuro

ISSN: $1809-1261$

UNIEURO, Brasília, número 18, 2016, pp. 226-259.

seus efeitos convergentes e divergentes, além das considerações finais.

II. REVISÃO TEÓRICA

Com o governo do ex-presidente Luiz Inácio Lula da Silva, em 2004 foi implementada, a Medida Provisória no 132/2003, um extenso programa nacional de transferência de renda para os pobres, o PBF, cuja criação consistia em dois objetivos: reduzir a pobreza e interromper seu ciclo intergeracional. O PBF, além de transferir renda para combater a pobreza, contém dois eixos principais: o combate a problemas ligados aos aspectos de pobreza e desigualdade de renda possui caráter multidimensional. Portanto, não trata apenas de questões monetárias, mas sim a transferência de renda, que esses problemas são equalizados (PINTO, CORONEL E FILHO, 2015).

O PBF nada mais é do que fruto da unificação das ações de transferência de renda do governo federal em 2003, em especial dos Programas Bolsa Escola, Bolsa Alimentação, Auxílio-Gás e do Cartão Alimentação, além do Cadastro Único. Seu modelo de gestão conjuga esforços dos três níveis de governo (Federal, Estadual e Municipal) por meio da criação de uma rede intergovernamental que viabiliza uma coordenação articulada com diferentes políticas sociais, de modo que respeite $a$ interdependência entre os entes da Administração Pública Federados. A respeitar a autonomia dos entes federados e a interdependência entre eles (LICIO, MESQUISTA E CURRALERO, 2011).

Entre as condicionalidades do PBF pode-se descrever três que segundo Vieira (2015). A primeira consiste na área da saúde onde 
Artigo original

Hegemonia - Revista Eletrônica de Relações Internacionais do Centro Universitário Unieuro

ISSN: $1809-1261$

UNIEURO, Brasília, número 18, 2016, pp. 226-259.

deve ocorrer o acompanhamento de mulheres entre 14 a 44 anos, em especial o pré-natal ou nutrizes, a vacinação de crianças menores de sete anos, seu crescimento e desenvolvimento. A segunda consiste na educação de crianças e adolescentes entre 6 e 15 anos de idade o quais devem estar matriculados com frequência escolar mínima de $85 \%$. Já na terceira condicionalidade encontra-se os governos que cabe a eles a responsabilidade pela oferta dos serviços públicos relacionados à saúde, educação e assistência social as famílias beneficiadas alvo do programa.

Em uma análise geral os valores repassados aos beneficiados pelo Ipea (Instituto de Pesquisa Econômica Aplicada) data os anos de 2004 a 2012. Os Estados apresentam conforme a escala utilizada gerando um maior nível de eficiência no desenvolvimento regional a partir dos recursos do Bolsa Família estão o estão Amapá, Distrito Federal, Goiás, Rio de Janeiro, Rio Grande do Sul, Santa Catarina e São Paulo. Já os Estado do Acre (99,29\%), Mato Grosso do Sul $(99,37 \%)$ e Roraima (99,44\%), apesar de não apresentarem eficiência média de $100 \%$, podem ser também classificados como de alto desempenho de eficiência no desenvolvimento regional nos resultados da gestão do programa (PINTO, CORONEL E FILHO, 2015).

Os autores Licio, Mesquista e Curralero (2011) citam que as famílias beneficiárias devem ser acompanhadas pelas áreas de saúde, educação e assistência social no âmbito das condicionalidades do Programa, em uma perspectiva de reforçar o direito de acesso a essas políticas universais, cuja sua finalidade de monitoramento permite que o programa monitore e identifique as famílias em situação de maior vulnerabilidade. 
Artigo original

Hegemonia - Revista Eletrônica de Relações Internacionais do Centro Universitário Unieuro

ISSN: $1809-1261$

UNIEURO, Brasília, número 18, 2016, pp. 226-259.

Um ponto de discussão frequente é que o programa seria assistencialista e como tal tenderia a aumentar a dependência dos pobres em vez de encorajar a responsabilidade e a autonomia. Todavia, se o programa operar de forma menos extensa acaba por fim em incorrer no erro de exclusão, um resultado paradoxal se considerar que o objetivo de tais programas é a eliminação da pobreza e inclusão social (KERSTENETZKY, 2009).

\section{TEORIA DO DESENVOLVIMENTO LOCAL}

Desenvolver localmente um país em que um ambiente econômico e político com as características de exclusão que foram criadas exigem a compreensão de mudanças em longo prazo e um amadurecimento e consolidação de uma democracia participativa. Os fatores de desenvolvimento local exigem a integração entre os diversos atores da sociedade e principalmente o conhecimento das demandas sociais que foram excluídas. Para construir resultados positivos os atores sociais locais devem ser incluídos e o uso de sua criatividade também deve criar oportunidades a diversas regiões.

Para Han (2009), o desenvolvimento local parte do pressuposto de que os agentes da sociedade (governos, cidadãos, empresas e organizações da sociedade civil) de determinada localidade estão integradas formando um consenso sobre as características econômicas da região observando não só a importância do desenvolvimento não somente econômico, mas sim centrado nas pessoas e no ambiente (WON SUKHAN, 2015).

O desenvolvimento só poderá ser considerado efetivo, se reunir a soma do desenvolvimento humano, social e sustentável, devido ao 
Artigo original

Hegemonia - Revista Eletrônica de Relações Internacionais do Centro Universitário Unieuro

ISSN: $1809-1261$

UNIEURO, Brasília, número 18, 2016, pp. 226-259.

fato de buscar-se de forma concreta a melhoria de vida das pessoas (desenvolvimento humano) e da sociedade como um todo (desenvolvimento social), com a preocupação tanto do presente como do futuro, ou seja, das pessoas que vivem hoje e das pessoas que viverão amanhã, levando então ao desenvolvimento sustentável. Em suma o desenvolvimento deve refletir o progresso da sociedade em suas múltiplas dimensões e não apenas na dimensão econômica (MARTINELLI, 2004).

Encarar o desenvolvimento local segundo Ávila (2006a) requer uma relação com suas próprias periferias, carências e pobrezas interna e socioeconomicamente desequilibradas. O desenvolvimento local resolve-se pelo menos em termos de amenização da injustiça social seja por emprego, salário e participativo aproveitamento dos potenciais locais como geradores de renda e bem-estar social nas comunidades visadas.

O Desenvolvimento no Local ( $\mathrm{DnL}$ ) refere a um empreendimento ou iniciativa a que se atribui a qualificação, por gerar emprego e expectativa de arrecadação de impostos e circulação de bens e dinheiro. Já o desenvolvimento para o Local $(\mathrm{DpL})$ refere-se à ideia de desenvolvimento além de se situar no local como sede física, gera atividades e efeitos benéficos às comunidades, vai aos locaiscomunidades, seja de caráter político-eleitoral, assistencialista, promocionalista e filantrópico, de modo geral, pensados e postos em prática por entidades/pessoas (ÁVILA, 2012).

Para Sanches (2013), a cada dia torna-se cada vez mais nítida a noção que desenvolvimento deva implicar em melhor qualidade de vida para os membros de uma comunidade, pois analisar um gráfico demonstrando o crescimento anual do PIB de uma região não 
Artigo original

Hegemonia - Revista Eletrônica de Relações Internacionais do Centro Universitário Unieuro

ISSN: $1809-1261$

UNIEURO, Brasília, número 18, 2016, pp. 226-259.

representa necessariamente que houve melhora no mesmo patamar das condições de vida da população, na inclusão social, no acesso a bons serviços nas áreas da saúde e da educação ou que a população esteja se alimentando melhor e por fim vivendo com mais dignidade.

De acordo com Marsiglia (1996) apud Rabaioli, Rezende e Maciel (2015) a lógica do Desenvolvimento Local esta baseada na existência e fortalecimento dos diversos atores territoriais os quais estão dispostos a levar adiante projetos sendo de interesses comuns ou até mesmo divergentes ou conflituosos que, entretanto, com a capacidade de ação e de formulação de propostas socioeconômicas estimulem potencialidades e contribuam para uma melhor qualidade de vida da sociedade.

Ávila (2012) importa-se em frisar a importância de distinguir absolutamente a assistência social de assistencialismo. Para ele a assistência social é um motor-de-arranque para o desenvolvimento social, técnico, científico, cultural, entre outros. Já o assistencialismo seria um crime, apesar de possuir um caráter social, técnico, científico, cultural, entretanto inibidor, assassino e degenerador da iniciativa de pessoas e comunidades em curto, médio ou longo prazo.

O Desenvolvimento Local no contexto de sua semântica gera uma tendência mundial, em virtude da questão econômica. O surgimento de nações mais desenvolvidas e nações menos desenvolvidas de modo geral vêm trazendo sacrifícios as nações menos desenvolvidas de um modo social e econômico. O crescimento das experiências de desenvolvimento local está reforçado por um processo de descentralização político-administrativa, em que no Brasil as políticas públicas buscam o desenvolvimento com base nas 
Artigo original

Hegemonia - Revista Eletrônica de Relações Internacionais do Centro Universitário Unieuro

ISSN: $1809-1261$

UNIEURO, Brasília, número 18, 2016, pp. 226-259.

comunidades locais ou mais precisamente nos municípios (MARQUES, 2013).

\section{TEORIA DO DL E POLÍTICAS PÚBLICAS}

Os autores Oliveira e Martins (2003), descrevem três principais objeções antepostas à avaliação de impacto de políticas públicas sendo elas: dificuldade de mensuração, dificuldade de divulgação dos resultados e a inutilidade da avaliação de impacto. Em sua explicação o autor explica que as duas primeiras contêm implicações imediatas contra o exercício da cidadania afrontando o sentido dos processos orçamentários públicos, de prestação de contas e da gestão, respectivamente. Na combinação na segunda com a terceira objeção há a necessidade de serem rediscutidas no ciclo das políticas públicas. Já com a combinação das três objeções a situação encontrase na contramão do que a sociedade espera da relação sociedadeestado, pois o discurso do governo não é a efetividade das suas ações.

Do ponto de vista de desenvolvimento o PBF pode parecer dramático, pois de um lado, o mero cumprimento das imposições não é em si um indicador de aumento de capacitação (em virtude da precariedade dos serviços) e de outro lado a manutenção das famílias no programa não é nem sequer garantia de que elas se tenham beneficiado de qualquer serviço devido ao fato de que a falta de uma das condicionalidades já faz com que o programa seja suspenso. E de outro lado também o programa não prevê nenhuma punição para a falha do governo em cumprir com o seu dever de oferecer os serviços (KERSTENETZKY, 2009). 
Artigo original

Hegemonia - Revista Eletrônica de Relações Internacionais do Centro Universitário Unieuro

ISSN: $1809-1261$

UNIEURO, Brasília, número 18, 2016, pp. 226-259.

Nas condicionalidades proposta pelo PBF mostra-se evidente a participação do Ministério do Desenvolvimento Social (MDS), do Ministério da Saúde (MS) e do Ministério da Educação (MEC), que são corresponsáveis pelo programa e precisam sensibilizar pactuar e mobilizar seus sistemas de políticas públicas a fim de reforçar o vínculo entre as políticas setoriais e o público mais pobre, alvo de possíveis dificuldades para acessar tais serviços, valorizando então o Princípio da Equidade em políticas públicas de caráter universal (LICIO, MESQUISTA E CURRALERO, 2011).

Ainda para os autores supracitados a participação em cada esfera do governo atua da seguinte forma: a União financia e regulamenta o Programa, os Municípios garantem grande parte da execução no nível municipal, e os Estados com atuação mis restritos participa na gestão do programa com a finalidade de apoiar os Municípios na distribuição do programa, uma vez que cabe a estes o cadastramento e a gestão de benefícios, assim como a prestação dos serviços básicos de saúde, educação e assistência social e articulação de programas complementares e a base na oferta do poder local, ou seja, poder municipal.

\section{POLITICAS PÚBLICAS}

O Programa Bolsa Família é conhecido e executado como um programa de transferência direta de renda direcionado às famílias em situação de pobreza e extrema pobreza inscritas no Cadastro Único (CADÚNICO). Entre as competências e responsabilidade da União destaca-se o Ministério do Desenvolvimento Social e Combate à Fome (MDS) como o responsável pela coordenação, gestão e 
Artigo original

Hegemonia - Revista Eletrônica de Relações Internacionais do Centro Universitário Unieuro

ISSN: $1809-1261$

UNIEURO, Brasília, número 18, 2016, pp. 226-259.

operacionalização do PBF. A realização de processos necessários à concessão e ao pagamento das transferências, a gestão do Cadastramento Único do Governo Federal e supervisão do cumprimento das condicionalidades que reforça o acesso aos direitos básicos na educação, assistência social e saúde (ALMEIDA, FONSECA E FERRO, 2015).

Para Licio, Mesquista e Curralero (2011) a coordenação de políticas públicas em sistemas federativos implica especificar o arranjo institucional no qual esta se insere, de modo a compreender a dinâmica das relações entre os atores responsáveis pela sua implementação. Para Abrucio (2005) toda federação deriva de uma situação federalista, caracterizada pela existência de heterogeneidades de cunho territorial, étnico, linguístico, socioeconômico, cultural e político que dividem uma determinada nação.

Um dos grandes temas sociais, como a pobreza, demanda respostas em níveis intra e intergovernamental, sendo que no nível intragovernamental concretiza-se por meio de políticas baseadas em conhecimentos e recursos de diversos órgãos de um mesmo nível de governo e na conjunção de esforços. Já o nível intergovernamental implica na coordenação entre instituições de governos distintos, de igual ou diferente nível (MORENO, 2007).

Ainda para o Moreno (2007) a intersetorialidade e a gestão intergovernamental são modalidades de respostas cada vez mais frequentes da administração pública a um entorno complexo podendo enfim provocar modificações no arranjo federativo das políticas públicas e ainda demandar maior capacidade de coordenação. Por fim essa situação aplica-se ao programa de desenvolvimento do PBF 
Artigo original

Hegemonia - Revista Eletrônica de Relações Internacionais do Centro Universitário Unieuro

ISSN: $1809-1261$

UNIEURO, Brasília, número 18, 2016, pp. 226-259.

quando comparados a padrões intergovernamentais da transferência de renda (hierarquizado) assim como o padrão adotado nas suas dimensões intersetoriais.

Há 14 anos a Declaração do Milênio estabeleceu metas concretas para melhorar as condições de vida na qual tem conseguido importantes objetos logrados no prazo do ano de 2015. Entre os oito objetivos do milênio traçados pela Organização das Nações Unidas (2014) encontra-se o objetivo 1 que trata da erradicação da pobreza extrema e da fome, a meta é de reduzir pela metade, entre os anos de 1990 e 2015, as porcentagens de pessoas cujo rendimento seja inferior a um dólar por dia. O mesmo objetivo traz alguns dados de interesse citando que em todo o mundo nos anos de 2011 a 2013, cerca de 173 milhões de pessoas a menos sofrem de fome crônica no mundo se comparado a os anos de 1990 a 1992.

Por sua a vez a Vigente Constituição da República Federativa do Brasil (1988) por se tratar de uma Constituição programática, ou seja, se caracteriza por conter normas definidoras de tarefas e programas de ação a serem concretizados pelos poderes públicos, traz o artigo $6^{\circ} \mathrm{com}$ a seguinte redação: "São direitos sociais a educação, a saúde, a alimentação, o trabalho, a moradia, o lazer, a segurança, a previdência social, a proteção à maternidade e à infância, a assistência aos desamparados, na forma desta Constituição". 
Artigo original

Hegemonia - Revista Eletrônica de Relações Internacionais do Centro Universitário Unieuro

ISSN: $1809-1261$

UNIEURO, Brasília, número 18, 2016, pp. 226-259.

\section{V.I MÉTODOS DE AVALIAÇÃO DE POLÍTICAS PÚBLICAS}

Os métodos de avaliação de políticas públicas consistem na análise dos programas sociais, com vistas a mensurar se os objetivos do programa foram atingidos. Em outras palavras, é verificar se de fato o público-alvo foi beneficiado com a política pública implementada.

Explica Cotta (2001), que a classificação da avaliação tem sido realizada "em função do seu timing (antes, durante ou depois da implementação da política ou programa), da posição do avaliador em relação ao objeto avaliado (interna, externa ou semi-independente) e da natureza do objeto avaliado (contexto, insumos, processo e resultados) ".

A avaliação ocorrida antes (ex ante) é mais estimulada em programas voltados à infraestrutura econômica e ao desenvolvimento urbano, cujo objetivo consistem em análises de custo-benefício, custo-efetividade, das taxas de retorno econômico dos investimentos previstos (LOBO, 1998).

A avaliação intermediária, denominada também de formativa, segundo Ala-Harja e Helgason, (2000) é realizada na implementação do programa com o intuito de adquirir conhecimentos em relação ao processo de aprendizagem que se deseja melhorar. Seu objetivo é auxiliar e contribuir para a gestão, implementação e desenvolvimento do programa, com ênfase à aplicabilidade direta dos resultados.

Já as avaliações que ocorrem depois da implementação da política ou programa são denominadas de ex post ou somativas, e visam trabalhar com impactos e processos, ou seja, verifica-se a eficácia do programa. (LOBO, 1998; ALA-HARJA e HELGASON, 2000). 
Artigo original

Hegemonia - Revista Eletrônica de Relações Internacionais do Centro Universitário Unieuro

ISSN: $1809-1261$

UNIEURO, Brasília, número 18, 2016, pp. 226-259.

Como a literatura sobre o tema é bastante vasta, o presente trabalho não vai esgotar os métodos de avaliação de políticas públicas, tampouco definirá toda a classificação da avaliação trazida por Cotta (2001). Aqui serão escolhidas técnicas que já avaliaram determinados resultados do Programa Bolsa Família.

\subsubsection{Avaliação de Impacto}

Inicialmente, trata-se do método por avaliação de impacto, cujo objetivo dessa modalidade de pesquisas de avaliação de resultados é mensurar os impactos da intervenção do Estado sobre o público-alvo dos programas e projeto sociais (JANNUZZI e PINTO. 2013).

Esse método é adotado quando o programa social já se encontra em fase mais avançada, ou seja, problemas de implantação e quais serão as ações desenvolvidas não existem mais (JANNUZZI e PINTO. 2013).

Por outro lado, adverte Jannuzzi (2011) que conflitos éticos e restrições operacionais limitam esse tipo de abordagem no mundo real de avaliação de programas públicos, ao passo que devido a essa complexidade da realidade social é necessário método mais eclético para responder às necessidades dos gestores na tomada de decisões alusivas ao programa.

Para avaliação das políticas públicas através do método de avaliação de impacto, deve se valer de definições quasiexperimentais de pesquisa. É realizado uma comparação ao longo de um período da performance socioeconômica de uma amostra de indivíduos ou famílias beneficiárias do programa social em análise, denominadas de grupo de tratamento, com outros sujeitos, 
Artigo original

Hegemonia - Revista Eletrônica de Relações Internacionais do Centro Universitário Unieuro

ISSN: $1809-1261$

UNIEURO, Brasília, número 18, 2016, pp. 226-259.

denominados grupo de controle e que não são beneficiários, mas com características e submetidos a condições semelhantes no período estudado (JANNUZZI e PINTO, 2013).

Por esse método é possível constatar se ao longo do tempo o grupo dos beneficiários do PBF (grupo de tratamento) evoluiu em relação ao grupo dos não beneficiários do PBF (grupo de controle), por meio uma ou várias variáveis-respostas, entendidas como reveladoras dos efeitos diferenciais do programa sobre seu públicoalvo (JANNUZZI e PINTO, 2013).

O quadro a seguir ilustra como é feita a comparação acima descrita, utilizando-se da pesquisa de Jannuzzi e Pinto (2013), no trabalho denominado "Bolsa Família e seus impactos nas condições de vida da população brasileira: Uma síntese dos principais achados da pesquisa de avaliação de impacto do Bolsa Família II".

TABELA 1

Distribuiçáo dos domicílios investigados pela Avaliaçáo de Impacto do Programa Bolsa Familia - $2^{2}$ Rodada (AIBF II), segundo condiçăo na $1^{2}$ rodada (AIBF I)

\begin{tabular}{|c|c|c|c|c|}
\hline & \multirow{2}{*}{$\begin{array}{l}\text { Condiçáo de recebimento do beneficio } \\
\text { Beneficiários do Bolsa Familia }\end{array}$} & \multicolumn{3}{|c|}{ AlBF II (2009) } \\
\hline & & $\begin{array}{l}\text { Beneficiảrios do Bolsa } \\
\text { Famnlia }\end{array}$ & $\begin{array}{l}\text { Não beneficiários do } \\
\text { Bolsa Famllila }\end{array}$ & Total \\
\hline \multirow{4}{*}{$\begin{array}{l}\text { AlBF I } \\
(2005)\end{array}$} & Beneficiários do Bolsa Famllia & 1.844 & 929 & 2.773 \\
\hline & Nāo beneficiários do Bolsa Famillia, insccitos no Cadúnico & 1.121 & 1.352 & 2.473 \\
\hline & $\begin{array}{l}\text { Não beneficiários do Bolsa Famllia, não inscritos no } \\
\text { CadUUnico }\end{array}$ & 1.707 & 3.416 & 5.123 \\
\hline & Total & 4.672 & 5.697 & 10.369 \\
\hline
\end{tabular}

Obs.: a AlBF II encontrou 11.423 domicllios dos 15.426 entrevistados em 2005. Nesta tabela não constam os 1.064 domicllios que não pertencem aos grupos analisados na rodada de 2009.

Fonte: Jannuzzi e Pinto (2013) 
Artigo original

Hegemonia - Revista Eletrônica de Relações Internacionais do Centro Universitário Unieuro

ISSN: $1809-1261$

UNIEURO, Brasília, número 18, 2016, pp. 226-259.

Essa evolução pode ser analisada sob diversos aspectos investigados na avaliação de impacto do Bolsa Família, por exemplo, educação, saúde, trabalho e trabalho infantil, rendimentos, gastos individuais, etc.

Em relação à educação, a pesquisa de Jannuzzi e Pinto (2013), apontou que crianças beneficiárias do PBF apresentaram progressão escolar da ordem de 6 pontos percentuais maior que crianças de mesmo perfil socioeconômico não beneficiárias do PBF.

Os mesmo autores também demonstraram que PBF apresentou impactos efetivos na melhoria das condições de saúde de crianças beneficiárias, reduzindo a desnutrição aguda e garantindo cumprimento mais regular do esquema vacinal.

\subsubsection{Análise Envoltória de Dados - DEA}

A técnica de Análise Envoltória de Dados (DEA), tem como objetivo, verificar a eficiência de determinado programa e todos os aspectos que ele visa atingir. É uma medida de eficiência relativa, avaliando os recursos (inputs) utilizados em um processo ou programa e seus resultados (outputs).

Para o DEA é criado uma fronteira de eficiência, onde as DMUs (Unidade Decisórias) mais eficientes ficam sobre a fronteira, e as unidades decisórias menos eficientes ficam abaixo da fronteira.

Farrell (1957) apud Pinto, Coronel e Filho (2015) explica que a técnica da Análise Envoltória de Dados (DEA), surgiu na década de 50. Todavia, nos dizeres de Charnes, Cooper e Rhodes (1978), Banker, Charnes e Cooper (1984), apud Pinto, Coronel e Filho (2015), esse método somente tornou-se apto nas décadas de 70 e 
Artigo original

Hegemonia - Revista Eletrônica de Relações Internacionais do Centro Universitário Unieuro

ISSN: $1809-1261$

UNIEURO, Brasília, número 18, 2016, pp. 226-259.

80, em que houve a proposição de se medir a eficiência de processos por meio de análise de insumos (inputs) e produtos (outputs) não paramétricos de um processo.

Trata-se de um dos meios mais usuais em análise de fronteiras que realiza através de um conjunto de ferramentas matemáticas, avaliações comparativas dos resultados de um grupo de tomadores de decisão (Decision Making Unit ou DMU). A partir disso, são estabelecidas fronteiras de eficiência entre as DMUs avaliadas (SHAW, 2009).

Farrell (1957) apud Pinto, Coronel e Filho (2015) destaca, ainda, que na sua origem a Análise Envoltória de Dados era mensurada por um único conjunto de pesos dos inputs e outputs.

Diferente de outros métodos de avaliação, essa técnica não é voltada a uma tendência central, mas sim para fronteiras, como se vê esquema básico da análise envoltória de dados a seguir (PINTO, CORONEL e FILHO, 2015):

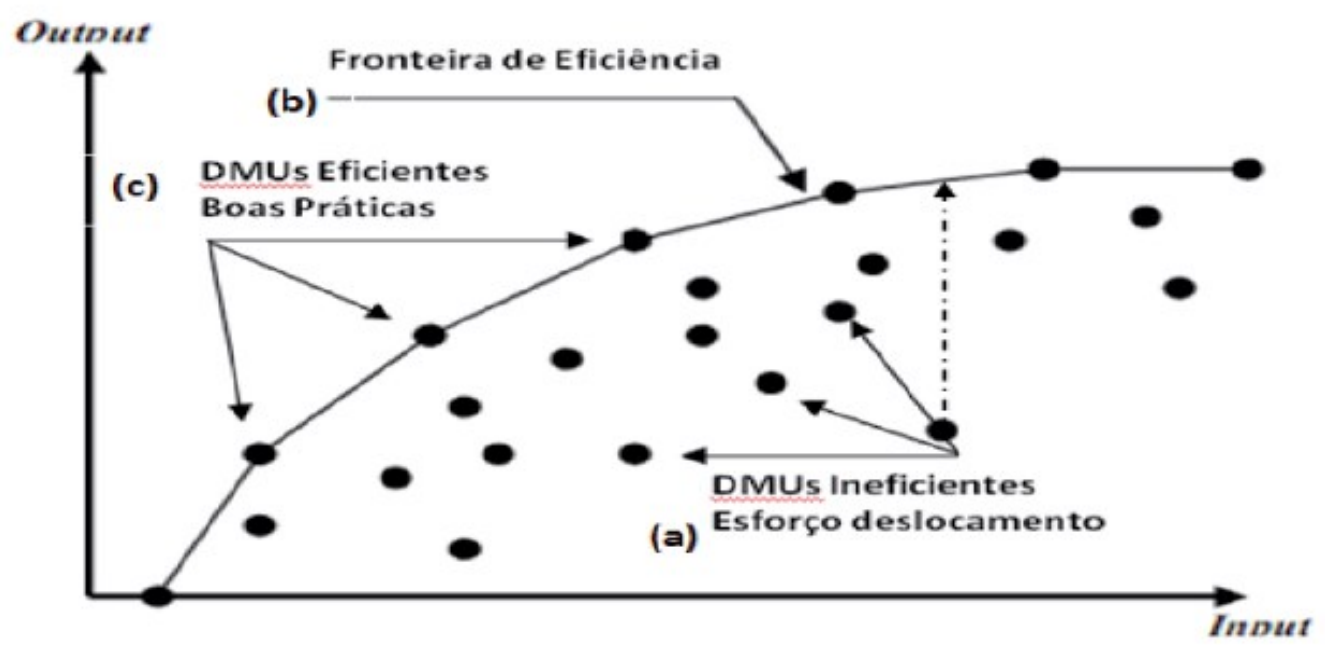

Fonte: Pedroso; Calmon; Bandeira (2009) apud Pinto, Coronel e Filho (2015). 
Artigo original

Hegemonia - Revista Eletrônica de Relações Internacionais do Centro Universitário Unieuro

ISSN: $1809-1261$

UNIEURO, Brasília, número 18, 2016, pp. 226-259.

Assim, apresenta resultados que não são obtidos em outros métodos, pois indica não só as relações de eficiência relativas a cada grupo de tomadores de decisão (Decision Making Unit ou DMU), mas também fornece informações sobre o que é necessário para ajustá-lo quando está ineficiente (Banker e Maindiratta, 1986 apud Pinto, Coronel e Filho, 2015).

No tocante à operacionalização desse método, Ferreira e Gomes (2009), explicam que, em geral, podemos seguir três etapas: 1) definição das DMUs; 2) escolha do método de DEA; e 3) seleção dos inputs e outputs que tenham importância para estabelecer a eficiência relativa das DMUs.

Valendo-se da pesquisa de Pinto, Coronel e Filho (2015) no trabalho intitulado "Eficiência no Desenvolvimento Regional Resultante do Programa Bolsa Família - Aplicação da Análise Envoltória de Dados (DEA) nos Estados e Regiões Brasileiras de 2004 a 2010" foram delimitados cada Estado brasileiro e o Distrito Federal como uma DMU, com o intuito de verificar a eficiência do PBF em todo território nacional, já que são unidades tomadoras de decisão autônomas junto aos seus municípios sobre o desempenho relativo do Programa.

No tocante ao método, os autores utilizaram-se do Variable Returns to Scale (VRS), verificando como se dava o resultado da eficiência dos repasses do programa.

Já com relação à escolha das variáveis, o objetivo era transmitir os impactos mais importantes no desenvolvimento regional resultantes do PBF, escolhendo, por exemplos, número de beneficiados pelo Bolsa Família (Input 1), valores repassados aos beneficiados pelo Bolsa Família - em reais - (Input 2), renda média 
Artigo original

Hegemonia - Revista Eletrônica de Relações Internacionais do Centro Universitário Unieuro

ISSN: $1809-1261$

UNIEURO, Brasília, número 18, 2016, pp. 226-259.

de familiar - em reais - (Output 1), número de leitos hospitalares por habitante - \% - (Output 2), etc (PINTO, CORONEL e FILHO, 2015).

De acordo com os resultados encontrados pelos autores Pinto, Coronel e Filho (2015) na pesquisa acima apontada, o processo de eficiência no que diz respeito à gestão do programa foi divergente em cada Estado brasileiro, sendo alguns classificados como referência aos demais por ter atingido um maior índice de eficiência no desenvolvimento regional, por exemplo, Acre, Amapá, Distrito Federal, Goiás, Mato Grosso do Sul, Rio de Janeiro, Rio Grande do Sul, Roraima, Santa Catarina e São Paulo.

Em sentido contrário, outros Estados possuíram menor eficiência nos resultados da gestão do Programa, a saber, Alagoas, Amazonas, Maranhão, Pará e Pernambuco, ou seja, todos localizados nas regiões Norte ou Nordeste (PINTO, CORONEL e FILHO, 2015).

Ainda nesse trabalho, os autores constatando a concentração de melhores práticas do Programa somente em algumas regiões, agruparam a análise dos Estados nas cinco grandes regiões brasileiras e identificaram aquela que apresenta melhor eficiência.

A tabela a seguir demonstra a eficiência média das Regiões brasileiras no período de 2004 a 2012. 
Artigo original

Hegemonia - Revista Eletrônica de Relações Internacionais do Centro Universitário Unieuro

ISSN: $1809-1261$

UNIEURO, Brasília, número 18, 2016, pp. 226-259.

Tabela 6 - Eficiência Média do Bolsa Família nas Regiões brasileiras nos anos 2004 a 2012 conforme os Modelos de Estudo

\begin{tabular}{lcc|}
\hline & \multicolumn{2}{c|}{ Eficiência Média por Modelo (\%) } \\
\cline { 2 - 3 } DMI: - Regiōes & Modelo 1 & Modelo 2 \\
Norte & 95,63 & 95,02 \\
Nordeste & 92,93 & 92,33 \\
Centro-Oeste & 98,96 & 98,59 \\
Sudeote & 99,11 & 98,96 \\
Sul & 99,63 & 99,10 \\
\hline
\end{tabular}

Fonte: Pinto, Coronel e Filho (2015).

Pois bem. Considerando 0 processo de eficiência no desenvolvimento regional para as Regiões brasileiras, o quadro retrata que no PBF quem se destaca é a Região Sul, pois foi a que apresentou maior índice de eficiência, seguindo pelas Regiões Sudeste, Centro-Oeste e Norte. Já a região Nordeste foi a que apresentou o menor grau de eficiência no desenvolvimento regional pelos recursos gerados pelo PBF (PINTO, CORONEL e FILHO, 2015).

\subsubsection{Regressão Logit/Probit}

Vários autores como Ferro, Kassouf e Levison (2009), Ferro e Nicollela (2007), Cardoso e Souza (2004) e Ribas e Soares (2011) utilizaram a mensuração do programa bolsa família através de regressão com modelos probabilísticos.

Esses modelos se baseiam em equação matemática com erros aleatórios e forma uma equação econométrica conforme, Figura 1 abaixo: 
Artigo original

Hegemonia - Revista Eletrônica de Relações Internacionais do Centro Universitário Unieuro

ISSN: $1809-1261$

UNIEURO, Brasília, número 18, 2016, pp. 226-259.

Figura 1: Modelo Econométrico

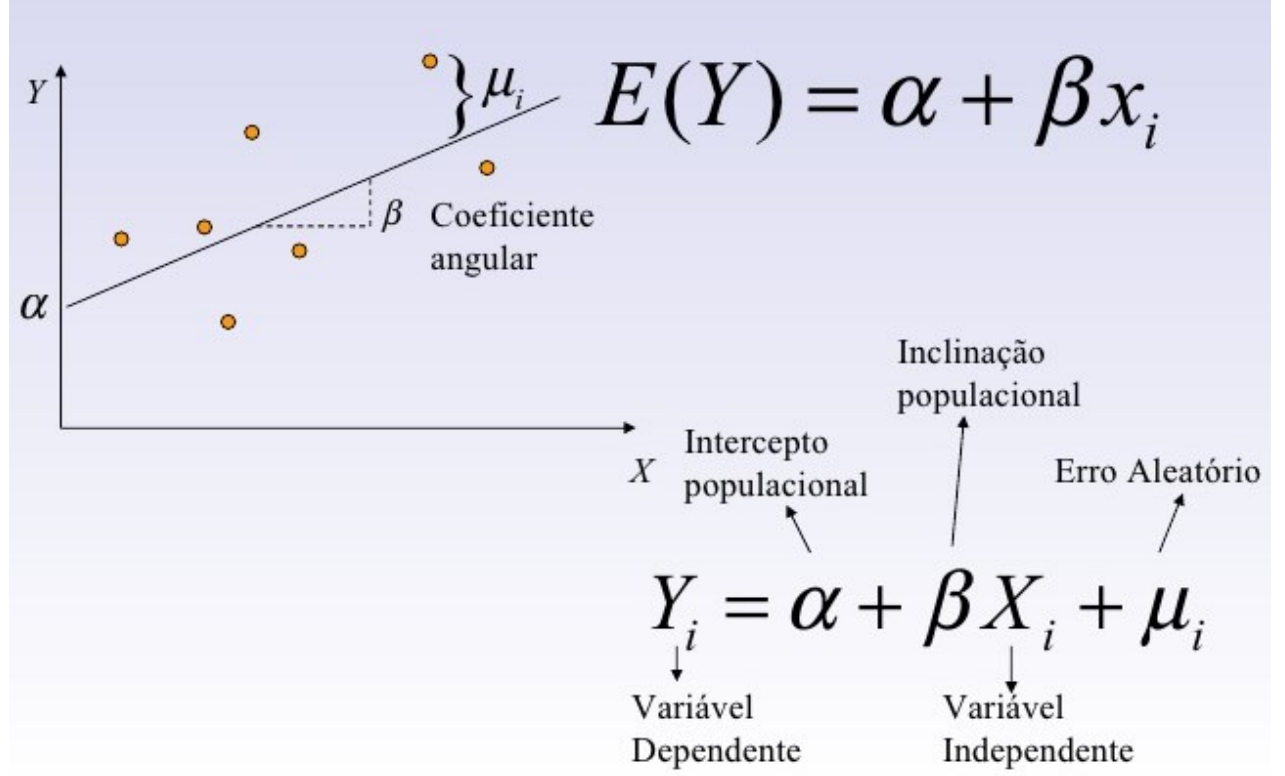

Nesse caso a mensuração da política é definida pelo efeito marginal que uma variável explicativa tem na variável dependente, por exemplo:

Qual o efeito de ter ou não ter bolsa família na renda da população de um determinado estado brasileiro?

O modelo seria:

Renda da População $\left(Y_{i}\right)=a+\beta$.Bolsa Família $+u_{i}$

Assim, com auxílio dos dados e de um programa estatístico é possível medir quanto o aumento de 1 (um) real gasto com o bolsa família, aumenta a renda da população. 
Artigo original

Hegemonia - Revista Eletrônica de Relações Internacionais do Centro Universitário Unieuro

ISSN: $1809-1261$

UNIEURO, Brasília, número 18, 2016, pp. 226-259.

\section{VI - METODOLOGIA}

Este artigo buscou investigar a política pública federal do PBF criado com a finalidade de desenvolvimento social e humano assim como os alicerces do desenvolvimento econômico e sustentável no país.

A investigação realizada ocorreu por meio da pesquisa exploratória, onde segundo Piovesan e Temporini (1995) a pesquisa exploratória caracteriza-se como um estudo preliminar realizado com a finalidade de adequar o instrumento que se pretende conhecer, tendo por objetivo a variável do estudo que se apresenta seu significado e o contexto em que se insere com o desenvolvimento de enfoques e percepções, percebendo então a realidade como ela é e não como o pesquisador pensa que seja.

A primeira fase exploratória da pesquisa buscou estudar e analisar a política pública já implantada pelo governo brasileiro e que está em pleno funcionamento até os dias atuais definida como o Programa Bolsa Família.

A segunda fase da pesquisa explorou os três métodos de mensuração mais utilizados na literatura para medir o impacto gerado pelo PBF no Brasil.

A terceira fase da pesquisa utiliza o quadro conceitual elaborado por Oliveira et al (2013) e compara os objetivos do programa bolsa família e sua convergência ou divergência com os indicadores de desenvolvimento local. 
Artigo original

Hegemonia - Revista Eletrônica de Relações Internacionais do Centro Universitário Unieuro

ISSN: $1809-1261$

UNIEURO, Brasília, número 18, 2016, pp. 226-259.

VII - RESULTADOS E DISCUSSÃO

O PBF pode funcionar como um alívio à pobreza. Em pesquisa divulgada pelo IBGE (2008) revelou o perfil do conjunto dos beneficiários como composto, de modo geral, de pessoas que trabalham em empregos precários no setor informal da economia, recebendo renda insuficiente para satisfazer necessidades básicas em que o valor é um complemento da renda essencial para o alívio das várias privações. Entre elas, a mais crítica a subnutrição infantil, sobretudo porque pode danificar permanentemente as capacitações das crianças, atualizando-se ao longo do ciclo da vida como baixo desempenho escolar e baixa capacidade para o exercício de muitas outras potencialidades humanas (KERSTENETZKY, 2009).

Para Soares, Ribas e Osório (2007) apud Kerstenetzky (2009) na redução da pobreza um dos objetivos do programa, as famílias elegíveis, classificadas como muito pobres ou pobres, recebem transferências em razão da intensidade da pobreza e do número de crianças na família, todavia as transferências não são suficientes para removê-las da condição de pobreza, apresentando não obstante um alívio à pobreza para famílias muito pobres e podem ter tido efeitos significativos sobre a subnutrição infantil.

Quando o PBF ampliou seus beneficiários, em função da renda, atingindo as famílias rurais de baixa renda e não apenas as famílias urbanas consideradas prioritárias de um ponto de vista nutricional como as crianças com idade inferir a cinco anos, nutrizes e gestantes. A renda transferida dessa ampliação no sentido de beneficiar a pobreza rural como um todo, todavia as famílias rurais não gastam com alimentos como indica a família urbana, mas sim como outro 
Artigo original

Hegemonia - Revista Eletrônica de Relações Internacionais do Centro Universitário Unieuro

ISSN: $1809-1261$

UNIEURO, Brasília, número 18, 2016, pp. 226-259.

processo de decisão quanto a seu uso, destacando-se que o papel da mulher como gestora dos recursos recebidos Programa Bolsa Família (DUARTE, SAMPAIO E SAMPAIO, 2009).

Uma importante relevância para o programa seria alcançar efetivamente o público alvo. Haveria a necessidade das pessoas se apresentarem e declararem sua pobreza perante o governo local, pois acontece que em diversos casos que as pessoas não possuem nem sequer informação sobre seus direitos e, portanto, sobre como receber os benefícios. Em outros casos então algumas pessoas elegíveis poderiam preferir evitar o estigma de viver por conta de benefícios sociais juntamente com o medo de uma dependência de longo prazo parece real, considerando que o programa não tem sido capaz de garantir acesso às portas de saída de modo importante (KERSTENETZKY, 2009).

O autor Kerstenetzky (2009) menciona ainda os possíveis erros na lista de beneficiários a qual é formada por um mix de informações providas pelos governos locais e informação estatisticamente tratada provida pelo Instituto de Pesquisa Econômica Aplicada (IPEA), mecanismo que pode não ser capaz de eliminar oportunidades de ação clientelística por parte de autoridades locais. E por fim uma razão que pode agir de modo não surpreendente seria a restrição orçamentária pura e simples. 
Artigo original

Hegemonia - Revista Eletrônica de Relações Internacionais do Centro Universitário Unieuro

ISSN: $1809-1261$

UNIEURO, Brasília, número 18, 2016, pp. 226-259.

Quadro: Convergências e Divergências entre a Teoria do DL e o PBF

\begin{tabular}{|c|c|c|}
\hline Indicadores & Desenvolvimento local & $\begin{array}{l}\text { Objetivos do Programa } \\
\text { Bolsa Família (PBF) }\end{array}$ \\
\hline $\begin{array}{l}1 . \quad \text { Capacidades- } \\
\text { Competências- } \\
\text { Habilidades }\end{array}$ & $\begin{array}{l}\text { Características básicas } \\
\text { dos indivíduos que } \\
\text { promovem mudanças } \\
\text { na dinâmica } \\
\text { desenvolvimentista. }\end{array}$ & $\begin{array}{l}\text { Desenvolver } \\
\text { habilidades para o } \\
\text { futuro das famílias que } \\
\text { recebem benefícios } \\
\text { com o programa, como } \\
\text { capacitação para o } \\
\text { trabalho. }\end{array}$ \\
\hline $\begin{array}{lrl}2 . & \text { Colaboração } & \text { de } \\
\text { agentes externos } & \end{array}$ & $\begin{array}{l}\text { Dependência inicial dos } \\
\text { agentes externos para } \\
\text { colaborar no processo } \\
\text { de desenvolvimento. }\end{array}$ & $\begin{array}{l}\text { O programa já é uma } \\
\text { colaboração externa, } \\
\text { objetiva o combate } \\
\text { pobreza e desigualdade } \\
\text { de renda, porém cria } \\
\text { dependência infinita. }\end{array}$ \\
\hline $\begin{array}{l}3 . \quad \text { Protagonismo } \\
\text { individual e coletivo }\end{array}$ & $\begin{array}{l}\text { A teoria do DL aborda } \\
\text { a importância da } \\
\text { capacidade individual e } \\
\text { coletiva do indivíduo ou } \\
\text { da comunidade para } \\
\text { desabrochar } \\
\text { estratégias de } \\
\text { desenvolvimento. }\end{array}$ & $\begin{array}{l}\text { Em relação à educação, } \\
\text { a pesquisa de Jannuzzi } \\
\text { e Pinto (2013), } \\
\text { apontou que crianças } \\
\text { beneficiárias do PBF } \\
\text { apresentaram } \\
\text { progressão escolar da } \\
\text { ordem de } 6 \text { pontos } \\
\text { percentuais maior que } \\
\text { crianças de mesmo } \\
\text { perfil socioeconômico }\end{array}$ \\
\hline
\end{tabular}


Artigo original

Hegemonia - Revista Eletrônica de Relações Internacionais do Centro Universitário Unieuro

ISSN: $1809-1261$

UNIEURO, Brasília, número 18, 2016, pp. 226-259.

\begin{tabular}{|c|c|c|}
\hline & & $\begin{array}{l}\text { não beneficiárias do } \\
\text { PBF. } \\
\text { (A educação pode ser } \\
\text { uma alavanca para o } \\
\text { protagonismo } \\
\text { individual e coletivo, } \\
\text { porém, depende dos } \\
\text { traços culturais). }\end{array}$ \\
\hline $\begin{array}{l}\text { 4. Perspectiva de } \\
\text { construção social }\end{array}$ & $\begin{array}{lr}\text { A dinâmica } & \text { da } \\
\text { construção social é a } \\
\text { principal contribuição } \\
\text { de } \\
\text { desenvolvimento com } \\
\text { características } \\
\text { endógenas. }\end{array}$ & $\begin{array}{l}\text { O PBF funciona } \\
\text { como um alívio a } \\
\text { pobreza, entre elas a } \\
\text { subnutrição infantil. } \\
\text { Todavia, as } \\
\text { transferências não são } \\
\text { suficientes para } \\
\text { removê-las da condição } \\
\text { de pobreza, não } \\
\text { apresentando então } \\
\text { nenhum indicio de } \\
\text { capital social. Não } \\
\text { sendo possível, } \\
\text { portanto, verificar uma } \\
\text { construção dinâmica } \\
\text { das características } \\
\text { endógenas ligadas ao } \\
\text { desenvolvimento local. }\end{array}$ \\
\hline
\end{tabular}


Artigo original

Hegemonia - Revista Eletrônica de Relações Internacionais do Centro Universitário Unieuro

ISSN: $1809-1261$

UNIEURO, Brasília, número 18, 2016, pp. 226-259.

\begin{tabular}{|c|c|c|}
\hline $\begin{array}{l}\text { 5. Fatores históricos e } \\
\text { culturais }\end{array}$ & $\begin{array}{l}\text { Os traços culturais e } \\
\text { históricos de uma } \\
\text { comunidade, região, } \\
\text { cidade ou país são } \\
\text { determinantes para o } \\
\text { desenvolvimento. }\end{array}$ & $\begin{array}{l}\text { O PBF não apresenta } \\
\text { desenvolvimento com } \\
\text { relação aos traços } \\
\text { culturais, uma vez que } \\
\text { o objetivo do programa } \\
\text { juntamente com a } \\
\text { responsabilidade do } \\
\text { governo é a oferta } \\
\text { relacionada à saúde, à } \\
\text { educação e à } \\
\text { assistência social as } \\
\text { famílias apenas com a } \\
\text { finalidade de retirada } \\
\text { das famílias } \\
\text { beneficiadas da } \\
\text { pobreza e desigualdade } \\
\text { de renda. }\end{array}$ \\
\hline
\end{tabular}

Fonte: OLIVEIRA, SAMBUICHI e SILVA (2013). Adaptado

\section{VIII - CONSIDERAÇÕES FINAIS}

Os resultados da pesquisa mostraram que o mero cumprimento das imposições do PBF não é em si um mero indicador de aumento da capacitação e a manutenção do programa, também não é garantia que as famílias sejam beneficiadas de fato, pois a falta de qualquer das três condicionalidades faz com que o programa seja suspenso, não prevendo nenhuma punição para a falha do governo com seu dever de oferecer os serviços. 
Artigo original

Hegemonia - Revista Eletrônica de Relações Internacionais do Centro Universitário Unieuro

ISSN: $1809-1261$

UNIEURO, Brasília, número 18, 2016, pp. 226-259.

Com relação à crítica do programa ser assistencialista ou não, deve-se pensar na proposta do mesmo, sendo que as condicionalidades que ofertam do Bolsa Família precisa estar envolvidas na mudança da dinâmica desenvolvimentista, desenvolvendo assim criar novas habilidades para o futuro das famílias beneficiárias, capacitando-as, não servindo apenas para o alívio da pobreza, uma vez que a transferência da renda não provar ser condição suficiente para essa remoção, o que pode degenerar a iniciativa das pessoas e comunidades ao curto, médio ou longo prazo, podendo até mesmo criar uma exclusão futura ao invés de uma inclusão.

As técnicas de avaliação das políticas públicas por meio de seus métodos de avaliação demonstraram que em relação à educação as crianças beneficiárias do PBF apresentaram progressão escolar da ordem de 6 pontos percentuais maior que crianças de mesmo perfil socioeconômico não beneficiárias do PBF.

Os Estados que apresentaram um índice maior eficiência, entretanto, não sendo essa de $100 \%$ foram Acre, Amapá, Distrito Federal, Goiás, Mato Grosso do Sul, Rio de Janeiro, Rio Grande do Sul, Roraima, Santa Catarina e São Paulo. Os demais Estados geralmente da região Nordeste, como Alagoas e Pernambuco, apresentaram menor eficiência, sendo, porém, os maiores beneficiados pelo PBF.

Pensar na teoria do desenvolvimento local aliada ao PBF, no processo de desenvolvimento da comunidade ou até mesmo no desenvolvimento da nação brasileira que apóia esse programa a mais de 10 anos, como uma solução para as famílias de baixo poder aquisitivo, deve demonstrar efetivamente seu crescimento. De acordo 
Artigo original

Hegemonia - Revista Eletrônica de Relações Internacionais do Centro Universitário Unieuro

ISSN: $1809-1261$

UNIEURO, Brasília, número 18, 2016, pp. 226-259.

com a tabela das convergências e divergências aliadas ao desenvolvimento local e ao programa o item 1 e 2 da mostraram ser convergente com seus indicadores uma vez que desenvolve habilidades para o futuro das famílias com a colaboração dos agentes externos.

Já com relação ao item 3 deve se pensar na educação como uma alavanca no protagonismo individual e coletivo, porém que depende dos traços culturais. $O$ item 4 possui uma divergência, pois 0 programa alivia a pobreza e a subnutrição infantil, entretanto não são suficientes para remove-la das condições de pobreza, não sendo possível ver a construção dinâmica. E por último o item 5 que a relação dos traços culturais e históricos apresenta também divergência uma vez que o objetivo do programa está relacionado à saúde, à educação e à assistência social as famílias.

\section{V.IV - REFERÊNCIAS}

ABRUCIO, F. L. A coordenação federativa no Brasil: a experiência do período FHC e os desafios do governo Lula. Revista de Sociologia e Política, n. 24, p. 41-67, 2005.

ALA-HARJA, Marjukka; HELGASON, Sigurdur. Em direção às melhores práticas de avaliação. Revista do Serviço Público, Brasília, v. 51, n. 4, p. 5-59, out./dez. 2000.

ALMEIDA, L. F.; FONSECA, V.; FERRO, S. R. O. P. B. Programa Bolsa Família e a política de educação: análise no estado de Sergipe. Políticas Públicas e Gestão Sócioeducacional. 2015. p.13. 
Artigo original

Hegemonia - Revista Eletrônica de Relações Internacionais do Centro Universitário Unieuro

ISSN: $1809-1261$

UNIEURO, Brasília, número 18, 2016, pp. 226-259.

ÁVILA, V. F. Cultura de sub/desenvolvimento e desenvolvimento local. Sobral-CE: Edições da (Universidade Estadual Vale do Acaraú (UVA), 2006a. p.60.

ÁVILA, V. F. Dupla relação entre Educação e Desenvolvimento Local (endógeno-emancipatório). Universidade Fumec. Belo Horizonte Ano 9 n. 12 p. 13-49 jan./jun. 2012.

BRASIL. Congresso Nacional. Constituição Federal do Brasil, de 5 de outubro de 1988. Diário Oficial da República Federativa do Brasil, Brasília, DF, 5 out. 1988.

CAVALCANTI. Mônica Maria de Arruda, Avaliação de Políticas Públicas e Programas Governamentais - Uma Abordagem Conceitual, sem ano.

COTTA, Tereza Cristina. Avaliação educacional e políticas públicas: a experiência do Sistema Nacional de Avaliação da Educação Básica (Saeb). Revista do Serviço Público, Brasília, v. 52, n. 4, p. 89-110, out./dez. 2001.

DUARTE, G. B.; SAMPAIO, B.; SAMPAIO, Y. Programa Bolsa Família: impacto das transferências sobre os gastos com alimentos em famílias rurais. Rev. Econ. Sociol. Rural vol.47 no.4 Brasília Oct./Dec. 2009. 13 paginas.

FERREIRA, C. M. C.; GOMES, A. P. Introdução à análise envoltória de dados: teoria modelos e aplicações. Viçosa: UFV, 2009.

IBGE - Instituto Brasileiro de Geografia e Estatística. (2008), Acesso a Transferências de Renda de Programas Sociais. Resultados da Pesquisa Nacional por Amostra de Domicílios - PNAD de 2006. Rio de Janeiro, IBGE. 
Artigo original

Hegemonia - Revista Eletrônica de Relações Internacionais do Centro Universitário Unieuro

ISSN: $1809-1261$

UNIEURO, Brasília, número 18, 2016, pp. 226-259.

JANNUZZI, P. M. Avaliação de programas sociais no Brasil: repensando práticas e metodologias das pesquisas avaliativas. Planejamento e politicas públicas, Brasília, v. 36, p. 251- 275, 2011. KERSTENETZKY, C. L. Redistribuição e Desenvolvimento? A Economia Política do Programa Bolsa Família. Revista de Ciências Sociais, Rio de Janeiro, Vol. 52, no 1, 2009, pp. 53 a 83.

LICIO, E. C; MESQUITA, C. S.; CURRALERO, C. R. B. desafios para a coordenação intergovernamental do programa bolsa família. São Paulo v. 51 n. 5 set /out . 2011 . p 458-470.

LOBO, Thereza. Avaliação de processos e impactos em programas sociais: algumas questões para reflexão. In: RICO, Elizabeth Melo (Org.). Avaliação de políticas sociais: uma questão em debate. São Paulo: Cortez, 1998. p. 75-84.

MARQUES, H. R. Desarrollo local em La escala humana: uma exigência Del siglo XXI. Campo Grande: Mundial, 2013. p.121.

MARSIGLIA, J. Desenvolvimento e gestão local: temas e atores em um cenário de mudanças. In: RABAIOLI, V.; REZENDE, E. C. P.; MACIEL, J. de C.. Desenvolvimento local e ativação de atores territoriais: um estudo de caso. Campo Grande: UCDB, 2015. p. 5375.

MARTINELLI, Dante P. Desenvolvimento local e o papel das pequenas e médias empresas. Dante Pinheiro Martinelli, André Joyal. Barueri, SP: Manole, 2004.

MORENO, O M. C. Transversalidad y coordinación de lãs políticas de estado enel federalismo. In: Concurso Del CLAD sobre Reforma del Estado y Modernización de La Administración Pública, 20, 2001, Caracas. ¿Cómo enfrentar losdesafíos de latransversalidad y de laintersectorialidadenlagestión pública? Caracas: CLAD, 2007. 
Artigo original

Hegemonia - Revista Eletrônica de Relações Internacionais do Centro Universitário Unieuro

ISSN: $1809-1261$

UNIEURO, Brasília, número 18, 2016, pp. 226-259.

OLIVEIRA, J.B; MARTINS, P. E. Avaliação do impacto de políticas públicas: uma proposta de medida da efetividade das ações de governo - educação e emprego na república da utopia. FGV/EBAPE, Programa de Estudos Administração Brasileira, Biblioteca Virtual de Administração Brasileira, 2003, p.18.

OLIVEIRA, M. A C; SAMBUICHI, R. H. R.; SILVA, A. P. M. Experiências agroecológicas brasileiras: uma análise à luz do desenvolvimento local. Rev. Bras. de Agroecologia, jun 2013, p. 14.

ORGANIZAÇÃO DAS NAÇÕES UNIDAS. Objetivo de Desarrollo Del Milenio. Nova York: ONU, 2014.

PINTO, N. G. M.; CORONEL, D. A.; FILHO, R. B. Eficiência no Desenvolvimento Regional Resultante do Programa Bolsa Família. Aplicação da Análise Envoltória de Dados (DEA) nos Estados e Regiões Brasileiras de 2004 a 2010. DESENVOLVIMENTO EM QUESTÃO Editora Unijuí. Ano 13, n. 31, jul./set.2015, p. 143-172.

PIOVESAN, A.; TEMPORINI, E. R. Pesquisa exploratória: procedimento metodológico para o estudo de fatores humanos no campo da saúde pública. Departamento de Prática de Saúde Pública da Faculdade de Saúde Pública - Universidade De São Paulo. 1995. 318-25 p.

SANCHES, Ronaldo São Romão. A agricultura familiar no município de Terenos - MS: perspectivas de sustentabilidade e desenvolvimento local. Dissertação de mestrado em desenvolvimento local Universidade Católica Dom Bosco, Campo Grande, 2013. 125 p.

SHAW, E. H. A general theory of systems performance criteria. International Journal of General Systems, v. 38, n. 8, p. 851-869, 2009. 
Artigo original

Hegemonia - Revista Eletrônica de Relações Internacionais do Centro Universitário Unieuro

ISSN: $1809-1261$

UNIEURO, Brasília, número 18, 2016, pp. 226-259.

SOARES, F. V.; RIBAS, R. P.; OSÓRIO, R. G. (2007), EvaluatingtheImpactofBrazil'sBolsa

Família:

CashTransferProgrammesinComparative Perspective". Evaluation Note, no 1, InternationalPoverty Centre, Brasília. IN: KERSTENETZKY, C. L. Redistribuição e Desenvolvimento? A Economia Política do Programa Bolsa Família. Revista de Ciências Sociais, Rio de Janeiro, Vol. 52, no 1, 2009, p. 53 a 83.

VIEIRA, F. C. C. O processo de subalternização das beneficiá rias do Programa Bolsa Família. Brasilia-DF, 2015. p.63

WON SUK HAN, G. Desenvolvimento local: os desafios frente à globalização hegemônica. Vitrine da Conjuntura, Curitiba, v.2, n.2, abril 2009. 12p. 